\title{
Modern trends and emerging practices applied by organisations operating in Slovakia
}

\author{
Andrea Cambalikova, Luboslav Szabo*
}

\begin{abstract}
The interest in the modern trends in management comes both from the academic field as well as from the practice. Based on the results of our research and literature review we compiled a theoretical basis related to the modern managerial methods and tools used in the organization. We researched the traditional factors of management, hard factors and soft factors, more specifically what importance in managing of the organization is assigned to each of them. Our research has shown that the soft factors of management consider enterprises in Slovakia as those more important. A drawback is a fact that respondents rated corporate culture as the least important factor, while the successful implementation of the most modern management trends requires a change in corporate culture therefore it should be an important part worth paying attention.
\end{abstract}

\section{Introduction}

There is a couple of new challenges enterprises are facing to, such as changing economic conditions, coupled with decreasing trust in markets, increasing pressures on natural resources and significant changes in customer and employee demographics. Due to globalization there is a turbulent growth of competition. Globalization of markets and businesses brings equal conditions for access to information, sources and technologies. [1] On account of that enterprises will need to react to meet these new challenges in order to be successful. It becomes necessary to adapt their traditional methods of business to changing circumstances and new opportunities in the market. The role of the managers of enterprises is to monitor these changes continuously, evaluate them and react accordingly. The changed environment has resulted into the creation of new management methods, techniques, tools and practices that enable organizations to adapt to the current trends in the market. Managers of the organizations apply several methods and tools and the final selection depends on

* prof. Ing. Luboslav Szabo, CSc., University of Economics in Bratislava, Faculty of Business Management, Department of Management. Dolnozemska cesta 1/b, 85235 Bratislava, Slovakia, email: luboslav.szabo@euba.sk, co-authors share 50\%.

Ing. Andrea Cambalikova, PhD., University of Economics in Bratislava, Faculty of Business Management, Department of Management. Dolnozemska cesta 1/b, 85235 Bratislava, Slovakia, email: andrea.cambalikova@euba.sk, co-authors share 50\%.

The contribution is a part of the solution task the Ministry of Education VEGA no. 1/0375/20 in the range $100 \%$. 
knowledge, skills and personal attributes of the manager as well as on his disposal to run a business and a working team. There were times when modern approaches to organization management were applied only by the largest companies and those that led the changes. Gradually, their knowledge and using are one of the market survival requirements. In recent years, the management methods and tools have been more and more becoming an integral part of the manager's work. Whether it is revenue-raising effort, innovation, improving quality and efficiency, as well as planning for the future, managers continually seek for helpful tools. In our fast-moving world, the winners will be companies that can sense change and respond accordingly.

\section{Methods}

The subject of the paper has been processed using the analysis of secondary data, the available foreign scientific literature related to the research issue, which is listed in the references. We have used a wide range of articles from scientific journals related to the processing issue and electronic resources. We have also worked with the results of the consulting companies' surveys, mainly with the results of an international survey conducted by Bain \& Company entitled "Management Tools \& Trends", which served us for the needs of comparison of the state in modern trends in management in the world and in the Slovakia. The object of the survey was represented by a sufficiently large and representative sample of enterprises operating in Slovakia for the purpose of realization a primary survey. The questionnaire survey was aimed at determining the extent of application of individual modern methods and tools used during realization of managerial functions, in different types of organizations operating in different sectors. When processing the research topic, primary data were obtained by the realization of the survey using standardized questionnaires and by the realization of a qualitative survey through interviews with the executives. Respondents, in view of the questionnaire focus, were mainly executives of companies, managing directors and managers at the least intermediate level of management. The survey was conducted in the year 2017 with a total sample of 203 enterprises.

\section{Results and Discussion}

In the first part of this chapter we provide a theoretical overview of modern management methods and procedures that we have identified based on a literature review. In this paper we deal with and evaluate thirteen such management methods and tools.

The most adequate performance measurement method used to identify and illustrate the main drivers of the business, and which offers also an important view on organization's strategy is the Balanced Scorecard model that aligns and focuses every part of the organisation on improving and implementing the strategy.

Benchmarking is the process of comparing one's business processes and performance metrics to industry bests and best practices from other companies. Dimensions typically measured are quality, time and cost.

Big data analytics (BDA) is defined as a holistic approach to managing, processing and analysing the $5 \mathrm{~V}$ data-related dimensions (i.e., volume, variety, velocity, veracity and value) to create actionable ideas for delivering sustained value, measuring performance and establishing competitive advantages. [2] The survey showed that the most powerful businesses use BDA tools up to five times more often than their less efficient competitors. This survey also confirmed that these tools bring added value to businesses. [3] Gartner listed the top 10 technology trends for the next five years. In their view, big data will be a revolution in many areas, including business, scientific research, public administration, etc. [4] The 
strong interest in big data analytics comes mainly from the financial services, healthcare and industrial sectors. [5]

Over the past several years have hundreds of managers talked about the negative impact of complexity on both productivity and workplace morale. This message has been reinforced by the findings of major CEO surveys conducted by IBM and KPMG, both of which identified complexity as a key business challenge. [6] For years, companies have been compelled to reduce complexity, by tool complexity reduction, in products, services, internal operations and assets, all to eliminate unnecessary variability while improving performance. [7]

Customer relationship management (CRM) refers to building one-to-one relationships with customers that can drive value for the firm. This manuscript discusses proven CRM strategies that companies can use as means of effective customer management (CM). [8] In the current period can be observed more intensive use of information technologies for collecting and storing information about clients. This trend is also reflected in the use of innovative approaches to relationship marketing, which gave rise to new types of customer relationship management (CRM). These are primarily electronic (eCRM) and social (SCRM) CRM. [9]

Digital transformation (DT) means the use of technology to radically improve performance or reach of enterprises. It is becoming a hot topic for companies across the globe. [10] DT opens new possibilities to improve operating efficiency, develop more accurate and agile planning, heighten vendor awareness and collaborate with business partners throughout the value chain. [11]

Employee engagement surveys examine the employee's connection to the company 's mission. Based on 7,939 business units in 36 companies, study [12] used meta-analysis to examine the relationship at the business-unit level between employee satisfactionengagement and the business-unit outcomes of customer satisfaction, productivity, profit, employee turnover, and accidents.

Change management refers to a set of basic tools or structures intended to keep any change effort under control. The goal is often to minimize the distractions and impacts of the change. [13] Top managers are not only important to the macro level of the organization, but they also have a key role in supporting the implementation of change management and direct transmission of information to all employees about the importance of change. [14]

Kotler and Armstrong [15] stated that customer satisfaction is the level of one's feelings after comparing products performance that gets along with his expectations. Customer satisfaction is a term frequently used in marketing. It means a measure of how products and services supplied by a company meet or surpass customer expectation. Customer satisfaction is defined as the number of customers, or percentage of total customers, whose reported experience with a firm, its products, or its services (ratings) exceeds specified satisfaction goals. This reffers to satisfaction and loyalty management.

Social media programs allow individuals and organizations to interact with their employees, customers and partners electronically across a range of devices. [16] Social media are Internet-based applications that build on the ideological and technological foundations of Web 2.0, allowing the creation and exchange of user generated contents. [17]

Strategic planning is an organization's process of defining its strategy, or direction, and making decisions on allocating its resources to pursue this strategy. The leader tries by strategic or long-range planning to assist the company in establishing priorities and to better serve the needs of the membership. [18]

Talent management (TM) is the systematic attraction, identification, development, engagement, retention and deployment of those individuals who are of particular value to an organisation, either in view of their 'high potential' for the future or because they are fulfilling business/operation-critical roles. [19] TM is management of high performing staff regardless of their position in the organisation. [20] 
Time management is the act or process of planning and exercising conscious control over the amount of time spent on specific activities, especially to increase effectiveness, efficiency or productivity. Senior teams can create time budgets and formal processes for allocating their time. Leaders can pay more attention to time when they address organizational-design matters such as spans of control, roles, and decision rights. Companies can ensure that individual leaders have the tools and incentives to manage their time effectively. [21]

Currently, innovations represent factor influencing not only competitive ability of business, but also population quality of life, environmental behaviour of citizens and businesses, social sphere, informational literacy of business. Innovations are considered to be result of utilisation of different stimulus, tools, techniques, which in practical application represent, apart from satisfaction of basic needs, something more for consumer „over added value“. [22] Businesses should be opened and flexible towards new market options, global production trends, modern technologies, innovations, research and development, quality working labor and creation of new organisational forms. [23]

The submitted paper is a part of more comprehensive research, wherein we have evaluated the application of modern trends in business management in Slovakia, in terms of methods and tools used by the realization of the management functions, namely: planning, organizing, staffing, coordinating, and controlling. In this part of the chapter we provide an analysis of achieved results compared with an international survey.

Before we proceed to evaluate modern management trends, methods and tools, we would like to point out the traditional approaches that the managers use. "Hard factors" in organizational management are the elements that can be formally defined and implemented in the enterprise and affect the functioning of the organization and its processes. They are the result of rational thinking and have a factual orientation. In each business, certain hard factors are present, forming a visible part of the environment. Respondents were required to rate the selected hard factors by attribution of importance (5- point scale, $1=$ very important, 5= totally unimportant). The results are shown in the Fig. 1, where most of the companies consider these factors generally important (score very important and rather important). Most of the respondents consider a very important business strategy, 106 of them (52\%). The company's business planning system has also been very positively valued, which implies the importance (very and rather) of 169 businesses, what is $84 \%$ of the research sample. The third most important element is the control system, what do think $70 \%$ of the respondents.

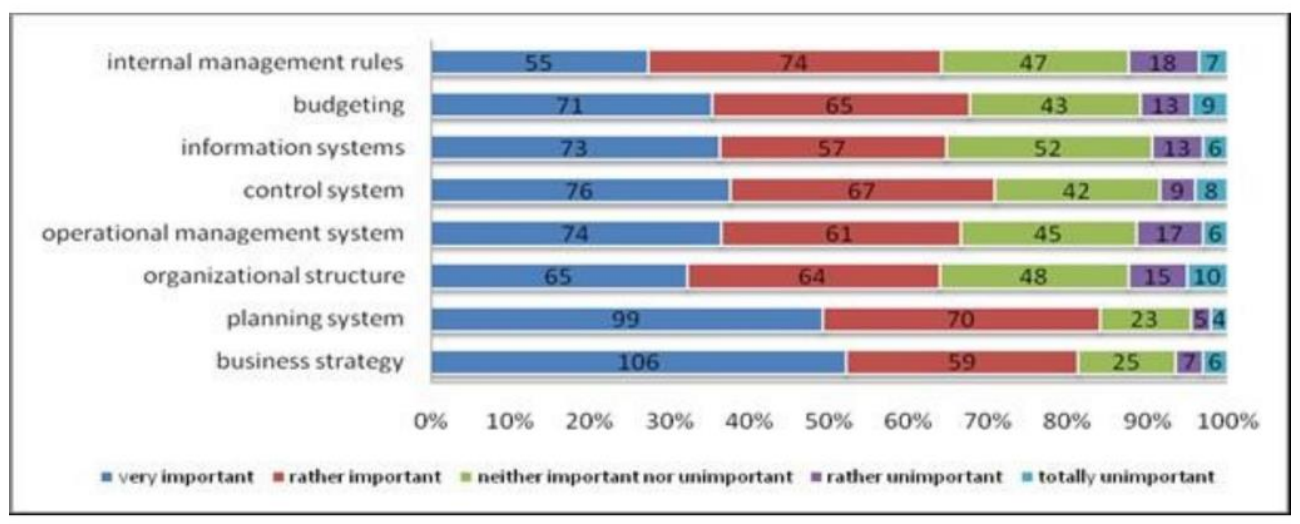

Fig. 1. Hard factors in management. 
Hard factors are supplemented by "soft factors" that exist due to the presence of people in enterprise, i.e. they relate to human factor and internal social relations within the enterprise. Soft factors cannot be formally defined and ordered. Based on the results from Fig. 2, the greatest importance (rating very and rather important) was placed by businesses on communication $(88 \%)$, and teamwork $(83 \%)$. On the other hand, the lack of importance (assessed by the options totally unimportant and rather unimportant) was attributed to the corporate culture (22 enterprises, i.e. $11 \%$ of enterprises) and to the qualification and skills improving (19 enterprises, i.e. 9\%). In the past, the trend was putting emphasis on hard factors and the soft ones were overlooked, what remains in many businesses to this day. At the present, the importance of the balance between hard and soft factors is growing. Their mutual balance and conditionality are key success factors in the market.

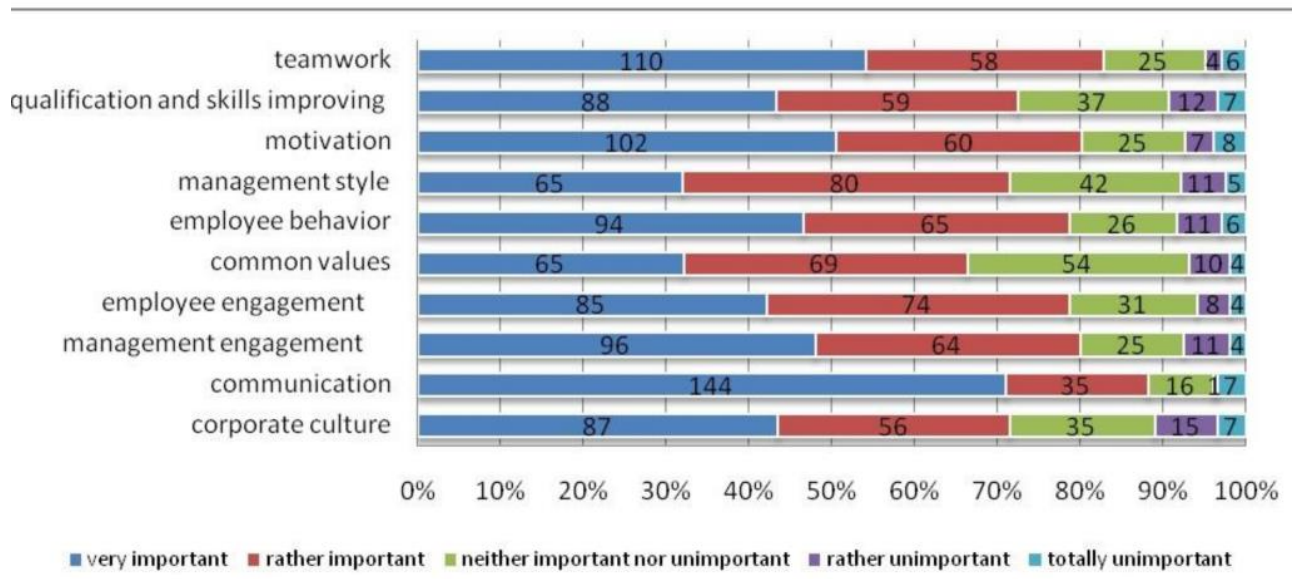

Fig. 2. Soft factors in management.

A drawback is a fact that respondents rated corporate culture as the least important factor, while the successful implementation of the most modern management trends requires a change in corporate culture therefore it should be an important part worth paying attention.

Table no. 1 shows a summary of thirteen researched modern trends in management and assessment their knowledge and use rates in absolute and relative frequencies.

Table 1. Knowledge and use of selected management trends. 


\begin{tabular}{|l|l|l|l|l|l|l|}
\hline \multirow{2}{*}{} & \multicolumn{2}{|c|}{ NOT KNOWN } & \multicolumn{2}{c|}{ KNOWN, NOT USED } & \multicolumn{2}{c|}{ USED } \\
\cline { 2 - 7 } & Absolute & Relative & Absolute & Relative & Absolute & Relative \\
\hline Balanced Scorecard & 106 & $52,20 \%$ & 45 & $22,20 \%$ & 52 & $25,60 \%$ \\
\hline Benchmarking & 45 & $22,20 \%$ & 46 & $22,70 \%$ & 112 & $55,10 \%$ \\
\hline Big Data Analytics & 75 & $36,90 \%$ & 66 & $32,50 \%$ & 62 & $30,60 \%$ \\
\hline Complexity Reduction & 100 & $49,30 \%$ & 47 & $23,20 \%$ & 56 & $27,50 \%$ \\
\hline $\begin{array}{l}\text { Customer Relationship } \\
\text { Management }\end{array}$ & 29 & $14,30 \%$ & 32 & $15,80 \%$ & 142 & $69,90 \%$ \\
\hline Digital Transformation & 90 & $44,30 \%$ & 45 & $22,20 \%$ & 68 & $33,50 \%$ \\
\hline $\begin{array}{l}\text { Employee Engagement } \\
\text { Surveys }\end{array}$ & 62 & $30,50 \%$ & 57 & $28,10 \%$ & 84 & $41,40 \%$ \\
\hline Change Management & 54 & $26,60 \%$ & 53 & $26,10 \%$ & 96 & $47,30 \%$ \\
\hline $\begin{array}{l}\text { Satisfaction and Loyalty } \\
\text { Management }\end{array}$ & 46 & $22,70 \%$ & 56 & $27,60 \%$ & 101 & $49,70 \%$ \\
\hline Social Media Programs & 48 & $23,60 \%$ & 59 & $29,10 \%$ & 96 & $47,30 \%$ \\
\hline Strategic Planning & 27 & $13,30 \%$ & 31 & $15,30 \%$ & 145 & $71,40 \%$ \\
\hline Talent Management & 66 & $32,50 \%$ & 55 & $27,10 \%$ & 82 & $40,40 \%$ \\
\hline Time Management & 36 & $17,70 \%$ & 45 & $22,20 \%$ & 122 & $60,10 \%$ \\
\hline
\end{tabular}

Respondents from the sample use strategic planning tool the most, i.e. 145 enterprises (71\%). For 27 respondents only (13\%) is this tool unknown. Slightly fewer enterprises use customer relationship management (CRM), 142 enterprises (70\%), while CRM do not know 29 respondents from the sample (14\%). The third most widely used management tool is time management, which is applied by 122 enterprises $(60 \%)$. As unknown was the tool marked by 32 enterprises $(18 \%)$. The least used tools by enterprises were a balanced scorecard $(26 \%)$, complexity reduction $(27.5 \%)$, and big data analytics (31\%). As we consider the survey of Bain \& Company [24], as the most comprehensive and relevant survey on modern trends and tools in management, we compared the results of our research with mentioned survey. In top 5 most used tools have strategic planning, CRM and benchmarking been in common identified in both surveys. The most applied managerial tool according to the international survey was CRM (used by $46 \%$ of companies). In our research, CRM was the second most widely used tool with the rate $70 \%$ in usage. In our research, the most widely used method was strategic planning (used by $71 \%$ of companies), what was the fourth most widely used method in the international survey, with the use of $44 \%$ of enterprises. The same percentage of enterprises also applies benchmarking, in our sample of enterprises it was up to $55 \%$. As we can see, in our research the rates of application of the most widely used tools are much higher than in the global survey. By contrast, for example, balanced scorecard and employee engagement surveys have been used less by companies operating in Slovakia than those involved in the global survey.

\section{References}

1. P. Richnak, K. Porubanova, Modern Trends in Business Logistics: Corporate Logistics in the 21st Century. Prague: Wolters Kluwer, 978-80-7598-183-7 (2018).

2. S. F. Wamba, A. Gunasekaran, S. Akter, S. J. F. Ren, R. Dubey, S. J. Childe, Big data analytics and firm performance: Effects of dynamic capabilities. Journal of Business Research 70, 356-365 (2017)

3. S. La Valle, Big data, analytics and the path from insights to value. MIT Sloan Management Review 52, p. 21-31, 1532-9194 (2011) 
4. P. Chen, Ch. Y. Zhang, Data-intensive applications, challenges, techniques and technologies: A survey on Big Data. Information Sciences, p. 314-347, 0020-0255 (2014)

5. D. Niknamian, Hadoop practitioners alike should rejoice in the rise of spark. [online]. Available: <http://dataconomy.com/2016/05/hadoop-practitioners-alike-rejoice-risespark-interview-altiscales-mike-maciag/> (2016)

6. R. Ashkenas, How To Reduce Complexity In Seven Simple Steps. [online]. Available: $<$ https://www.forbes.com/sites/ronashkenas/2014/03/24/how-to-reduce-complexity-inseven-simple-steps/\#28cbe091e43a> (2014)

7. R. Kozole, Reuse, recycle, and reduce complexity. [online]. Available: $<$ https://www.middleeast.atkearney.com/documents/20152/435359/Reuse_Recycle_Re duce_Complexity.pdf/c939734c-bf61-c1d8-e8e9-cadf3c8fa364?t=1493942411834> (2009)

8. V. Kumar, Customer relationship management, [online]. Available: < http://onlinelibrary.wiley.com/doi/10.1002/9781444316568.wiem01015/abstract?userIs Authenticated $=$ false $\&$ deniedAccessCustomisedMessage $=>(2010)$

9. M. Kubina, V. Lendel, Successful Application of Social CRM in The Company. Procedia Economics and Finance 23, p. 1190-1194, 2212-5671 (2015)

10. Capgemini Consulting, Digital transformation: a roadmap for billion-dollar organizations, [online]. Available: <https://www.capgemini.com/resources/digitaltransformation-a-roadmap-for-billiondollar-organizations/> (2011)

11. C. Sganzerla, C. Seixas, A. Conti, Disruptive innovation in digital mining. Procedia Engineering 138, p. 64-71, 1877-7058 (2016)

12. J. Harter, F. L. Schmidt, T. L. Hayes, Business-unit-level relationship between employee satisfaction, employee engagement, and business outcomes: a meta-analysis. Journal of Applied Psychology 87, p. 268-279, 268 -279 (2002)

13. J. Kotter, Change management vs. change leadership- what's the difference? [online]. Available: <https://www.forbes.com/sites/johnkotter/2011/07/12/change-managementvs-change-leadership-whats-the-difference/\#77d548e14cc6> (2011)

14. E. Ionescu, A. Meruta, R. Dragomiroiu, Role of managers in management of change. Procedia Economics and Finance 16, p. 293-298, 2212-5671 (2014)

15. P. Kotler, G. Amstrong, Principel of marketing. 15 th edition. Global edition, Person. ISBN 978-0133084047 (2012)

16. Bain \& Company, Social media programs [online]. Available: $<$ https://www.bain.com/insights/management-tools-social-media-programs/> (2013)

17. A. M. Kaplan, M. Haenlein, Users of the world, unite! The challenges and opportunities of Social Media. Business Horizons 53, p. 59-68, 0007-6813. (2010)

18. R. Bouhali, Y. Mekdad, H. Lebsir, L. Ferhka, Leader Roles for Innovation: Strategic Thinking and Planning. Procedia Social and Behavioral Sciences 181, p. 72-78, 1877 0428 (2015)

19. A. Weeks, Talent management [online]. Available: $<$ https://www.cipd.co.uk/knowledge/strategy/resourcing/talent-factsheet> (2020)

20. A. McDonnell, D. G. Collings, K. Mellahi, R. Schuler, Talent management: a systematic review and future prospects. European J. International Management 11, 1751-6757 (2017) 
21. F. Bevins, A. Smet, Making time management the organization's priority [online]. Available: $\quad<$ https://www.mckinsey.com/business-functions/organization/ourinsights/making-time-management-the-organizations-priority> (2013)

22. P. Richnak, K. Porubanova, Innovations in Logistics: Digitalization Challenges in Logistics. Prague: Wolters Kluwer, 978-80-7598-627-6 (2019)

23. K. Porubanova, P. Richnak, Usability of Intangible Assets in the Terms of Manufacturing Companies. Ad Alta: Journal Of Interdisciplinary Research 7, p.177180, 2464-6733 (2017)

24. D. Rigby, B. Bilodeau, Management Tools \& Trends 2015 [online]. Available: $<$ https://www.bain.com/insights/management-tools-and-trends-2015/> (2015) 